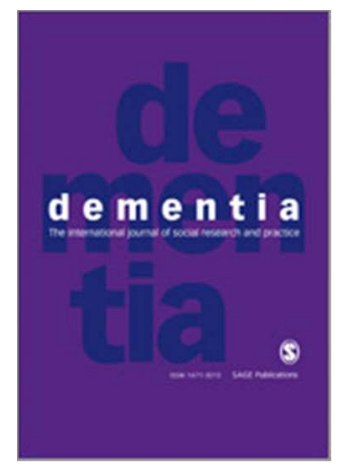

\title{
Participatory arts in care settings: A multiple case study: Innovative practice
}

\begin{tabular}{|r|l|}
\hline Journal: & Dementia: the international journal of social research and practice \\
\hline Manuscript ID & DEM-18-0013.R1 \\
\hline Origin of Contribution: & UK/Europe and the rest of the world \\
\hline Manuscript Type: & Innovative Practice \\
\hline Keywords: & $\begin{array}{l}\text { Dementia, Long term care, Creative arts, Non-pharmacological } \\
\text { interventions, Dementia care }\end{array}$ \\
& $\begin{array}{l}\text { This paper describes two case studies of arts interventions in UK care } \\
\text { settings. Visual arts and dance movement interventions were regularly } \\
\text { held in two settings. This paper draws on data from qualitative interviews, } \\
\text { reflective diary sheets and narrative monitoring reports to examine the } \\
\text { content, context, and process of the arts interventions within the care } \\
\text { settings. Activity coordinators play a crucial role in the success of arts } \\
\text { interventions in care setting through their knowledge and support of } \\
\text { residents. We recommend that preparatory consultations should take } \\
\text { place between arts practitioners and care personnel, as this seems to } \\
\text { improve participation and overall satisfaction. }\end{array}$ \\
\hline
\end{tabular}




\section{Background}

Creative and cultural opportunities can enrich the lives of older people, particularly of those living with dementia. Participatory arts interventions can positively impact mood, cognition and communication, as well as the quality of life of people living in residential care (Young, Camic, Tischler, 2016). Other outcomes include promoting learning, increasing confidence and socialisation (Young et al., 2016; Camic, Baker, Tischler, 2015). The benefits of visual arts activities have previously been evaluated for people with a diagnosis of mild to severe dementia compared to recreational activities alone. A randomised controlled trial conducted by Rusted, Sheppard and Waller (2006) demonstrated that, over a period of 40 weeks, participants in art therapy sessions improved in both mood and sociability. Likewise, results from an observational study utilising the Greater Cincinnati Chapter Well-Being Observational Tool (Kinney and Rentz, 2005) revealed that older adults had improved wellbeing during the arts intervention. These studies demonstrate that older adults who have a cognitive impairment are able to participate in artistic workshops. Moreover, participation in artistic programmes can encourage feelings of competence; in focus groups, people with dementia self-reported their satisfaction participating in cultural sessions (Ullán et al., 2011).

Benefits have been demonstrated in dance movement sessions for people with dementia. Findings from a systematic review reported that dance therapy reduced problematic behaviours, enhanced mood, socialisation and cognition in care home residents (GuzmánGarcía, Mukaetova-Ladinska, James, 2012). A meta-analysis reported that dance sessions may increase quality of life and positively affect wellbeing, mood and affect (Koch, Kunz ,Lykous, Cruz, 2014). For people with dementia, the opportunity for expression through nonverbal processes can be beneficial; dance movement can be used as a supplement or alternative to speech (Nystrom \& Lauritzen, 2005). These examples demonstrate that there is an opportunity to enhance the quality of life for people living with dementia by offering cultural activities in care settings.

The Imagine Arts programme, in Nottingham, is one of four national projects to be awarded a grant from Arts Council England and The Baring Foundation's Arts and Older People in Care fund. The programme aims to introduce arts practice that challenges, engages, stimulates and enables older people in care to have access to cultural opportunities. Each project is a collaboration between a national care home provider, arts providers, and the city council.

\section{Method}

A dual case study design was chosen to evaluate the arts intervention. Case studies enhance our understanding of how or why programmes work, making it a valuable tool in exploring complex interventions within specific settings (Yin, 2014). The exploratory case studies had the following aims i) to provide insight into the context, content and process of the sessions; ii) to explore the impact of the creative sessions on residents, care staff and arts practitioners iii) reflect on any influencing factors and challenges.

\section{Setting}

The two care homes under examination were selected for practical reasons as they fitted with the Imagine programme timing.

\section{Orchard Hill}


Orchard Hill $(\mathrm{OH})$ is a Local Authority care home providing housing for forty-two individuals requiring nursing or personal care, including those living with dementia.

\section{Arts Intervention: Theatre}

This intervention consisted of bespoke performance sessions, combining movement and music, facilitated by drama specialists, dance movement therapists and musicians supported by volunteers. These were held in the care home for a period of six weeks, with each session lasting approximately two hours. The intervention took place in a communal space within the care home.

\section{Redcliff Day Centre}

Redcliff Day Centre (RDC) is a registered charity, this purpose built centre offers day time activities and support for older people in the community five days per week.

\section{Arts Intervention: Carnival}

This intervention was designed to enable participants to engage with community events beyond their care setting. Participants, supported by professional artists, assisted in the creation of two large puppets, showcased in the local carnival parade as well as community and public settings.

\section{Data collection and analysis}

After the intervention, semi-structured interviews were conducted with arts practitioners $(\mathrm{N}=2)$, care setting managers $(\mathrm{N}=2)$ and activity coordinators $(\mathrm{ACs})(\mathrm{N}=2)$. Interviews were audio-recorded and transcribed. Documents, including reflective diary sheets $(\mathrm{N}=19)$ kept by the artists delivering the intervention and quarterly monitoring reports to the funders $(\mathrm{N}=10)$, were also included in the analysis. In addition, the researcher visited and observed the intervention in context. The data were analysed using thematic analysis (Braun and Clarke, 2006). The researcher immersed herself in the data by listening to the audio-recorded interviews and transcribing them verbatim. Data were completely coded; identifying concepts deemed relevant to the research questions. The codes were then categorised to develop themes based on central organising concepts; the themes were identified deductively, based on the research aims. Instances in the data which were perceived to accurately represent each theme were extracted. The extracts have been used to illustrate the content and meaning of each theme.

\section{Results}

The analysis led to the identification of five major themes that have a temporal sequence: organisational factors refers to the venue; expectations to what happens before the session(s); opportunities and staff support relate to within the session; and skills and sustainability is about what happens afterwards.

\section{Organisational factors}

Organisational and environmental features influenced the process of the sessions. These were twofold: i) the physical space available for the sessions; and ii) working with the existing routines of the care setting. Challenges associated with the physical setting included rearranging the furniture to make the space as functional as possible and the access the practitioner had to participants, due to the layout and facilities available. Practitioners described working creatively to overcome the problems of the space. Hosting the arts session 
in a shared space meant that passers-by were able to experience the beneficial effects of the session. Staff appreciated that the space was being used for a novel event and they could see resources, such as a piano, being utilised for residents' enjoyment:

I think it definitely did have a wider effect... areas can become a bit tedious with the same activity day in day out or no activity, so I definitely think it did brighten people's moods.

Arts Practitioner

Even though there was a dedicated room for activities, the intervention at $\mathrm{OH}$ took place in the lounge. Staff explained that the large and open plan lounge allowed more residents to participate. In both settings, the intervention had to accommodate existing routines of the facilities, including the weekly activity schedule organised by staff.

In residential care, the intervention became the main stimulus or residents, as opposed to the day centre where the main purpose of attendance was socialisation and activity. The differences in the creative environment, and consequently the practitioners' approach to the intervention, between the day centre and residential homes were highlighted:

The atmosphere is a little bit different because it is more residential, so you've got a hushed, more sedate environment. Generally [you are] coming in to try to whip a bit of excitement, interest, fun.

Arts Practitioner

It seemed that the main challenge for practitioners was to identify the purpose and expectations of the intervention whilst at the same time considering the working demands of a care setting.

\section{Opportunity for expression}

The second theme encompasses the enjoyment, of staff and residents, of the sessions. Residents were described as interacting with each other and with the facilitators, reacting and engaging to the stimuli:

I think the residents enjoy it. Some of them or most of them seem happy about it and they seem a bit joyous.

Care Team Leader

Seeing the residents happy resulted in satisfaction for the staff as well; the AC described the lasting impact that the sessions had:

When a resident talks about something afterwards to me and they did, that shows to me that it's made a mark on them.

Activity Coordinator

There appeared to be wider effects for individuals from being in a room with music and movement. The opportunity to interact with individuals and activities outside of the care setting was expressed as being valuable:

I think it's important for social interaction with people from the outside coming in. Most of them don't get to see the arts and those kind of things anymore. 


\section{Activity Coordinator}

One successful aspect of the intervention was the ability to bridge the divide between the care settings, cultural venues, and activities. Many residents had previously been involved with local arts activities and the staff perceived that the programme reawakened memories and enabled residents to participate in previously enjoyed pastimes:

One gentleman that attended, every time the Theatre comes in, he tells them that he worked on the theatre when it was being built...[they] took him to the Theatre, and he's been on stage and this all came about from this project which is fantastic. Activity Coordinator

This example demonstrates the lasting impact of this programme; offering staff the opportunity to celebrate the life history, or new successes, of their residents which can be shared within the care setting.

I think we all say just to hear music and people and hear people having fun going round the home is just wonderful. Activity Coordinator

Reported spill over and lasting effects for the wider context of the care setting included staff dancing to music and residents discussing the sessions after they had happened.

\section{Staff supporting engagement}

This theme refers to the way staff encourage and facilitate the access and experience of residents participating in arts sessions. ACs play a key role in supporting the engagement of the residents in the sessions. Staff were instrumental in assisting the practitioner and providing support to residents who required extra assistance:

Without [support staff] I would struggle to coordinate everyone and lead an activity as well.

Arts Practitioner

Most of the residents needed initial encouragement to attend the sessions; ACs had to work proactively to achieve attendance:

There [were] a few residents that don't like to venture out of their rooms or in their lounges or their corridors. I sort of sat with them and explained what was going on and saw them open up singing.

Activity Coordinator

Similarly, staff at RDC described how they gave residents information about the intervention in advance. This was to encourage participation and give ownership of the sessions:

They need to know as well, it's not fair just coming in and saying, "right you're doing this today". It is their centre, so we like to bring to them as much [information] in advance as we can.

Care Worker 
Utilising the knowledge of care staff was felt to positively influence the outcomes of the session. Practitioners incorporated staff insights about residents' preferences, for example favourite music, which facilitated greater engagement. Practitioners are afforded little time to get to know residents, therefore staff knowledge of residents' likes and dislikes, as well as their ability to interpret residents' responses to interventions could be a useful tool. Staff at RDC described how they select participants for the intervention based on their knowledge of members' likes and dislikes:

Once we know what kind of activity is coming in we gauge it to our members on that day....so we can say right [resident A] can interact really well with this project or there might be another group who will interact better.

Care Worker

Other challenges of staff involvement included becoming immersed in the activities themselves, disadvantaging the residents they were assisting:

Sometimes the volunteers also get too involved themselves by the activities...people who might need the help aren't [getting it] so sometimes that's a little bit difficult to manage.

Arts Practitioner

\section{Expectations}

Expectations is an overarching theme regarding the way practitioners and care staff perceive their roles and responsibilities and how this influences the intervention. Having clear expectations of individuals participating in the intervention was highlighted as an important aspect of facilitation. Practitioners felt conflicted about the length of the sessions due to the expectations of the care setting. Sessions which focus on mobility and physical activity need to be flexible in length and content to cater for the abilities and needs of the residents:

I did sometimes think that care homes think that someone is going to come in for at least two hours and it feels like a morning activity, but I think the expectation around something that is more physical and moving it's quite hard to sustain that. Arts Practitioner

A designated consultation briefing was considered a desirable future action by both the practitioners and the ACs. This briefing would serve two functions i) to gather information from the practitioners about the sessions, thereby to ease facilitation ii) to impart pertinent information to the practitioner about what usually works best in the setting. Dialogue between the care setting and practitioner was emphasised as important to fully realise the potential of the arts sessions. For example, one practitioner described how they were not able to fully utilise facilities, such as a piano, until later in the sessions.

The AC was responsible for coordinating the sessions and specified as a valuable resource by the practitioners, particularly when wider staff members were less accommodating:

The staff who are contacts and links support very good so times you get other general staff who [have] got other duties and other responsibilities... or you get loud conversations happening nearby not trying to talk to the room because they are not appreciating to take their conversation elsewhere... it is so valuable to have activity 
coordinators or that link who know the centre, know the people, know the staff who can do that groundwork.

Arts Practitioner

It was reported, and expected, that wider staff generally do not participate in activities within the home unless specifically requested by the AC:

We don't get involved because we let [the AC] do it obviously unless we stood and watched for a few minutes because we're quite busy.

Care Team Leader

The main reasons staff felt they could not get involved with the sessions was because i) the focus on providing physical care took priority over social needs and ii) because the responsibility of daily activities lay with the AC.

\section{Skills and sustainability}

Gaining skills was a two-way process for practitioners and ACs. The sessions gave the practitioner a greater understanding and appreciation for working in care settings with an elderly population. They developed skills which could be used in future projects and transferred into other areas of work:

It helped me to pull together my understanding of similarities between different care homes and what things might be different or figuring out what pretty much always works and what things can be a little bit more challenging for individuals.

Arts Practitioner

The active participation of the AC in the sessions contributed to the sustainability of the programme. The generation of new ideas and inspiration, from observing the practitioners, was considered a successful outcome:

It just gives us new ideas for different activities and different projects ourselves...I mean, I've taken part in them but I'm no artist yet [it] just broadens ideas.

Care Worker

The success of the programme was attributed to the effective working relationship between the practitioner and the AC. However, it appeared that other care staff were unable to fully engage with the programming:

The AC attended every session but the care staff seemed to be too busy with basic care to participate. This wasn't a problem to us, but they have not been able to offer any feedback on what we did or whether or not they feel they could do something like this themselves.

Arts Practitioner

\section{Discussion}

This dual case study gives insight into the context and content of an arts programme. These findings suggest that participatory arts interventions may be successfully employed within care settings. ACs were given the opportunity to gain new skills and creative techniques which can be implemented in the future, maintaining the positive impact of the sessions, and contributing to the legacy of the programme. 
The support of the AC was identified as an important factor, in terms of motivating and supporting residents to attend the sessions, and the innate knowledge they had of residents' needs, abilities and preferences. Artistic sessions which require higher facilitator to participant ratios, such as visual arts workshops, would benefit from the attendance of care staff in addition to the ACs. It would also give wider staff the opportunity to feedback to practitioners regarding the sessions, with the potential to create a community of practice where care personnel and practitioners could learn from each other's skillset. This would require a cultural change within the setting, where social and emotional care, including meaningful activity, is prioritised alongside physical care needs. At RDC, all staff members were expected to participate and facilitate activities for residents, in contrast to $\mathrm{OH}$ where the responsibility lay solely with the AC. Residential facilities have additional pressure to complete daily caring tasks, beyond what is required from a day centre. This may impact the delivery of arts interventions in these settings, particularly how care personnel engage with creative activities within their workplace.

The staff selection of participants noted in these cases has both advantages and disadvantages. Residents selected may be encouraged to participate in activities they enjoy; however, this may limit the choice of the residents, potentially diminishing their autonomy. Or it may exclude some residents from sessions that they would have enjoyed. How staff and residents may be able to interact in arts sessions is worthy of further consideration. In some instances, staff may become overly involved, e.g. doing for the resident rather than doing with them. However, perhaps including staff members as equal participants could be done more often and could have experiential and other benefits.

It could be suggested that a consultation between practitioners and care personnel, to better inform each other before the commencement of an arts programme, would benefit the facilitation of the sessions (Broome, Dening, Schneider, 2017). A briefing would allow both parties to clarify the purpose of the arts intervention and establish realistic expectations. It also provides an opportunity to identify and address barriers, both contextual for example regarding residents' needs and abilities, or environmental such as working within the routines of the care home. This would enable the sessions to run more effectively from the outset. Moreover, it enables staff to pass information to their residents, empowering them to make decisions about attendance, or to encourage those who may be tentative.

\section{Limitations}

This is a small scale evaluation therefore there has limited transferability. In addition, it lacks the participants' accounts of the programme. However, common themes were identified in the data analysed which provide insight into the implementation and impact of participatory arts interventions in care settings.

\section{Conclusion and recommendations}

These case studies demonstrate that creative arts interventions are an engaging and enjoyable activity for older people living in residential care which may contribute to their wellbeing. The identification of influencing factors and challenges which impact on stakeholders may be beneficial for future arts practice in care settings. The support and collaboration of ACs were invaluable for the programme; arts programmes may benefit from briefings between arts practitioners and care personnel to clarify roles and responsibilities. Future research could evaluate the role of the $\mathrm{AC}$ within the care setting, and whether this enables or constrains 
staff participation in arts interventions. There is scope for participatory arts in residential care, and using the findings of this evaluation to implement sessions to have the most benefit.

\section{References}

Braun, V., \& Clarke, V. (2006). Using thematic analysis in psychology. Qualitative Research in Psychology,3(2), 77-101. doi:10.1191/1478088706qp063oa

Broome, E., Dening, T., Schneider, J. (2017). Facilitating Imagine Arts in residential care homes: the artists' perspectives. Arts and Health. Doi: 10.1080/17533015.2017.1413399

Camic, P. M., Baker, E. L., Tischler, V. (2015). Theorizing how art gallery interventions impact people with dementia and their caregivers. The Gerontologist., 56(6), 1033-1041. Doi: $10.1093 /$ geront/gvn063

Guzmán-García, A., Mukaetova-Ladinksa, E., \& James, I. (2012). Introducing a Latin ballroom dance class to people with dementia living in care homes, benefits and concerns: A pilot study. Dementia., 12(5), 523-535. doi:10.1177/1471301211429753

Kinney, J., \& Rentz, C. (2005). Observed well-being among individuals with dementia: Memories in the Making, an art program, versus other structured activity. American Journal of Alzheimer's Disease and other Dementias, 20, 220-227. doi:10.1177\%2F153331750502000406

Koch, S., Kunz, T., Lykou, S., Cruz, R. (2014). Effects of dance movement therapy and dance on health-related psychological outcomes: A meta-analysis. The Arts in Psychotherapy. 41. 46-64. Doi: 10.1016/j.aip.2013.10.004

Nyström, K., Lauritzen, S. O. (2005). Expressive bodies: demented persons' communication in a dance therapy context. Health. 9(3). 297-371. Doi: 10.1177/1363459305052902

Rusted, J., Sheppard, L., Waller, D. (2006). A Multi-centre Randomized Control Group Trial on the Use of Art Therapy for Older People with Dementia. Group Analysis. 39(4).517-536. Doi: $10.1177 / 0533316406071147$

Ullán, A. M., Belver, M. H., Badia, M., Moreno, C., Garrido, E., Gómez-Isla, J., ... Tejedor, L. (2012). Contributions of an artistic educational program for older people with early dementia: An exploratory study. Dementia, 12(4), 1-22. doi:10.1177/1471301211430650

Robert K. Yin. (2014). Case Study Research Design and Methods (5th ed.). Thousand Oaks, CA: Sage.

Young, R., Camic, P., Tischler, V. (2016). The impact of community-based arts and health interventions on cognition in people with dementia: A systematic literature review. Aging and Mental Health, 20(4), 337-351.. doi: 10.1080/13607863.1015.1011080 